\title{
Intravenous Thrombolysis with rt-PA in Patients with Acute Ischemic Stroke: Experience of Al-Azhar University Hospitals and Almaadi Military Hospital Stroke Units
}

\author{
Nabil H Mohamed ${ }^{1}$, Ahmed A Nemr ${ }^{2}$, Hussein A Elghareeb ${ }^{1}$, Elsayed E Abed ${ }^{1}$ \\ ${ }^{1}$ Departments of Neurology, Faculty of Medicine, Al-Azhar University, Cairo, Egypt \\ ${ }^{2}$ Departments of Neurology, Military Medical Academy, Cairo, Egypt \\ Corresponding author: Elsayed Elsayed Ahmed Mohamed Abed; Mobile: 01062635615; \\ Email: sayed_neuro@outlook.com
}

\begin{abstract}
Background: Ischemic stroke (IS) is defined as a focal neurologic deficit of sudden onset and of presumed ischemic origin that lasts at least 24 hours and is not associated with hemorrhage on computed tomography (CT) or magnetic resonance imaging (MRI) of the brain. About $87 \%$ of strokes are ischemic, the rest being hemorrhagic. Bleeding can develop inside areas of ischemia, a condition known as "hemorrhagic transformation" (HT). Definitive therapy within the first few hours is aimed to removing the blockage by breaking the clot down (thrombolysis), or by removing it mechanically (thrombectomy). Aim of the Work: was to correlate the safety of recombinant tissue plasminogen activator (rt-PA) in acute ischemic stroke (AIS) patients in Egypt. Subjects and Methods: A number of case series of patients with AIS who were treated at Stroke Units of Al-Azhar University Hospitals and Almaadi Military Hospital over a period of 1years within a time window were reported. Results: we observed a statistically significant correlation between AIS patients who were treated by thrombolysis in time window and vascular risk factors and many important infrastructure-logistic factors. Conclusions: It could be concluded that thrombolytic therapy is a good standard treatment in time window but many barriers in developing countries were found.
\end{abstract}

Keywords: Ischemic stroke, time window, rt-PA.

\section{INTRODUCTION}

Stroke is a clinical syndrome of rapidly developing symptoms and signs of focal loss of cerebral function with no apparent cause other than vascular origin, lasting more than 24 hours, or may lead to death before this ${ }^{(1)}$.Stroke is the rapidly developing loss of brain functions due to a focal or global disturbance in the blood vessels supplying blood to the brain and retina. This can be due to ischemia caused by thrombosis or embolism or due to a hemorrhage, thus the affected area of the brain is unable to function, leading to inability to move one or more limbs on one side of the body, inability to understand or formulate speech or inability to see one side of the visual field ${ }^{(2)}$. Because the vast majority of strokes are ischemic in etiology, the development of an effective treatment for clot dissolution was ground breaking. rt-PA was approved by the FDA in the mid-1990s for the rapid lysis of $\mathbf{I} \mathbf{S}^{(\mathbf{3})} \mathbf{I} . \mathbf{V}$ administration of rt-PA remains the only proven intervention for emergency management of AIS and the only approved therapy for AIS by the FDA. A strong correlation has been shown between arterial recanalization and neurological improvement in acute cerebral ischemia ${ }^{(4)}$.

The aim of the current work was to correlate the safety of rt-PA in AIS patients and search for cause of low number of patients who were treated by thrombolysis with rt-PA in Egypt.

\section{SUBJECTS AND METHODS}

This study included a total of 29AIS patients treated with rt-PA within a time window attending at At Stroke Units of AlAzhar University Hospitals and Almaadi Military Hospital. Approval of the ethical committee and a written informed consent from all the subjects were obtained. This study was conducted over 1 year between 2016and 2017. The study was approved by the Ethics Board of Al-Azhar University.

- Inclusions criteria, Clinical diagnosis of and $\mathbf{C T}$ brain consistent with AIS. 
- Exclusion criteria, gastrointestinal or urinary tract bleeding within the preceding 21 days, Major surgery within the preceding 14 days or Lumber puncture, arterial puncture at non compressible site at this weak, pregnancy or recent hemorrhage.

Every subject was subjected to: CT brain before thrombolysis, laboratory assessment, including (CBC, renal function tests, PT, aPTT and serum level of $\mathrm{Na} \& \mathrm{~K}$ ). The dose of rt-PA was $\mathbf{0 . 9} \mathbf{~ m g} / \mathbf{k g}$ body weight with a maximum of $90 \mathrm{mg}$. 1/10 of total dose of rt- PA was given I.V in a bolus and the remaining 9/10 during 1 hour under continuous clinical assessment and monitoring of vital signs frequently.

\section{RESULTS}

- The mean age of 29 patients of AIS patients was $62.55 \pm 9.94$ years.

- 10 patients had IHD with percentage (34.5\%).7 patients were with AF with percentage $(24.1 \%) .3$ patients were smokers with percentage (10.3\%).one patients had previous CVS with percentage (3.4\%). As in (table 1)

Table (1): The frequency of different risk factors:

\begin{tabular}{|c|c|c|}
\hline & $\mathbf{A F}$ & $7(24.1 \%)$ \\
\hline $\begin{array}{l}\text { Risk } \\
\text { factors }\end{array}$ & $\begin{array}{l}\text { cerebro vascular } \\
\text { stroke (CVS) } \\
\text { ischemic heart } \\
\text { disease (IHD) } \\
\text { Smoking }\end{array}$ & $\begin{array}{l}1(3.4 \%) \\
10(34.5 \%) \\
3(10.3 \%)\end{array}$ \\
\hline
\end{tabular}

The Initial median NIHSS and its range and different findings in CT brain in relation to number of patients showed in these table(2)

Table (2): The Initial median NIHSS and its range and different findings in CT brain in relation to number of patients:

\begin{tabular}{|l|l|c|}
\hline \multicolumn{2}{|l|}{} & No.=29 \\
\hline $\begin{array}{l}\text { Initial } \\
\text { NIHSS }\end{array}$ & $\begin{array}{l}\text { Range } \\
\text { Median }\end{array}$ & $11(9-13)$ \\
\hline $\begin{array}{l}\text { Intial } \\
\text { CT } \\
\text { brain }\end{array}$ & $\begin{array}{l}\text { Dense MCA } \\
\text { sign }\end{array}$ & NAD \\
\hline
\end{tabular}

There was no significant values between NIHSS \% changes in relation to age, time to (ER \& needle) from stroke onset, time to needle from ER, initial NIHSS and NIHSS changes 2 hours post injection as (P-value $>0.05$ ) as showed in table (3).

Table (3): The comparison between NIHSS $\%$ changes in relation to age, time to (ER \& needle) from stroke onset, time to needle from ER, initial NIHSS and NIHSS changes $2 \& 24$ hours post injection in studied group

\begin{tabular}{|l|c|c|}
\hline \multirow{2}{*}{} & \multicolumn{2}{|c|}{ NIHSS \% change } \\
\cline { 2 - 3 } & $\mathbf{r}$ & P-value \\
\hline Age & 0.072 & 0.710 \\
\hline $\begin{array}{l}\text { Time to ER from } \\
\text { stroke onset }\end{array}$ & 0.002 & 0.990 \\
\hline $\begin{array}{l}\text { Time to needle from } \\
\text { stroke onset }\end{array}$ & 0.017 & 0.932 \\
\hline ER to needle time & -0.164 & 0.396 \\
\hline Initial NIHSS & -0.157 & 0.415 \\
\hline $\begin{array}{l}\text { NIHSS change 2H } \\
\text { post injection }\end{array}$ & 0.167 & 0.387 \\
\hline $\begin{array}{l}\text { NIHSS change 24H } \\
\text { post injection }\end{array}$ & $0.756 * *$ & 0.001 \\
\hline
\end{tabular}

There was no significant values between NIHSS \% changes in relation to all risk factors as (P-value >0.05) as showed in table (4).

Table (4): The comparison between NIHSS $\%$ changes in relation to risk factors in our studied group:

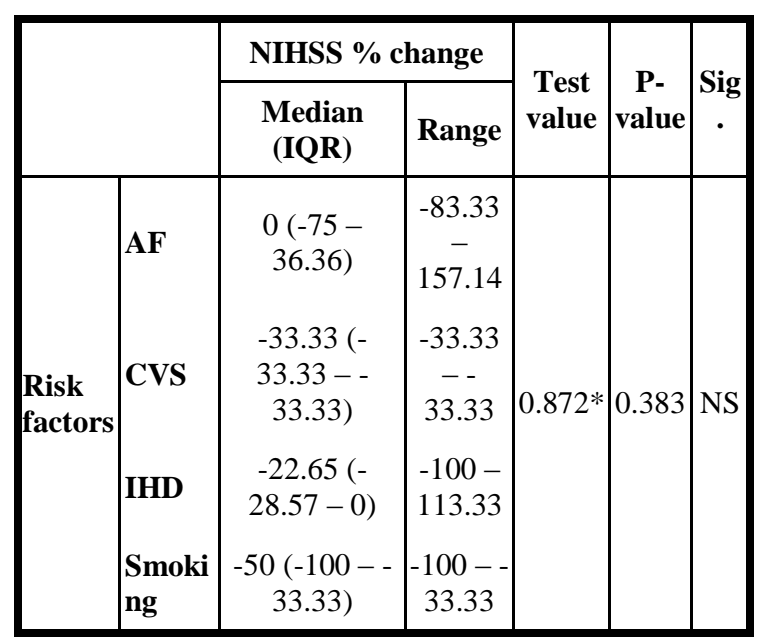

There was highly significant values between NIHSS \% changes in relation to symptomatic ICH and the patients who died as (P-value < 0.05) as showed in table $(5)$ 
Table (5): The comparison between NIHSS $\%$ changes in relation to developed symptomatic ICH, and who died post I.VrtPA injection in our studied group

\begin{tabular}{|c|c|c|c|c|c|c|c|}
\hline & \multicolumn{3}{|c|}{ NIHSS \% change } & & \multirow{2}{*}{$\begin{array}{c}\text { P- } \\
\text { val } \\
\text { ue }\end{array}$} & \multirow[b]{2}{*}{$\begin{array}{l}\mathrm{Si} \\
\text { g. }\end{array}$} \\
\hline & & $\begin{array}{c}\text { Medi } \\
\text { an } \\
(I Q R)\end{array}$ & Range & & & & \\
\hline $\begin{array}{l}\text { Symptom } \\
\text { atic ICH }\end{array}$ & \begin{tabular}{|l}
$\mathrm{No}$ \\
$\mathrm{Ye}$ \\
$\mathrm{Y}$
\end{tabular} & $\begin{array}{c}-26.79 \\
(-50- \\
0) \\
113.3 \\
3(50 \\
- \\
157.1 \\
4)\end{array}$ & $\begin{array}{l}-100-100 \\
50-157.14\end{array}$ & & $\begin{array}{c}2.65 \\
2 *\end{array}$ & $\begin{array}{c}0.00 \\
8\end{array}$ & $\begin{array}{c}\mathrm{H} \\
\mathrm{S}\end{array}$ \\
\hline Death & \begin{tabular}{|l}
$\mathrm{No}$ \\
$\mathrm{Ye}$ \\
$\mathrm{s}$
\end{tabular} & $\begin{array}{c}-26.79 \\
(-50- \\
0) \\
\\
113.3 \\
3(100 \\
- \\
157.1 \\
4)\end{array}$ & $\begin{array}{l}-100-100 \\
100\end{array}$ & $\begin{array}{l}1 \\
5 \\
7\end{array}$ & $\begin{array}{c}2.75 \\
9^{*}\end{array}$ & $\begin{array}{c}0.00 \\
6\end{array}$ & $\begin{array}{c}\mathrm{H} \\
\mathrm{S}\end{array}$ \\
\hline
\end{tabular}

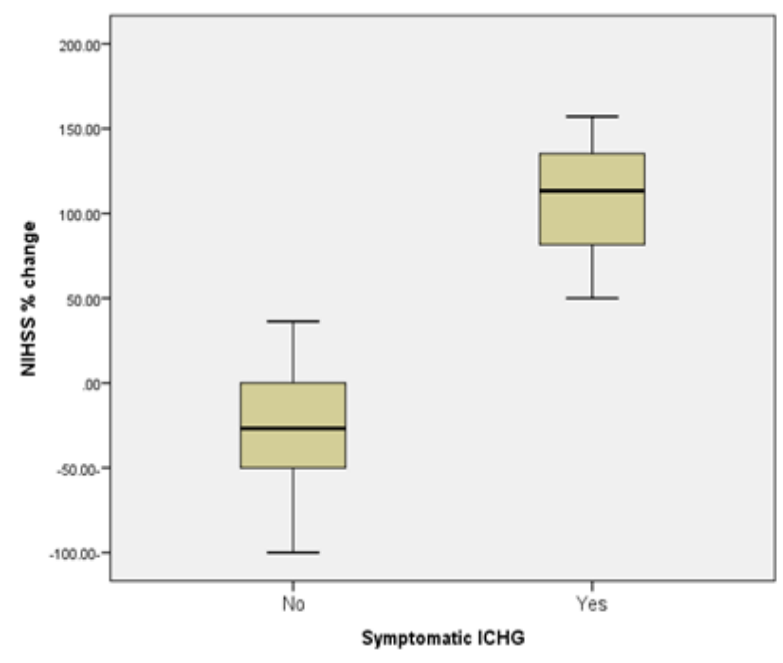

Figure (1): symptomatic ICH.

There was no significant values between NIHSS \% changes in relation to Asymptomatic ICH and who survived and developed other complication other than ICH as (P-value >0.05) as showed in table (6)

Table (6): The comparison between NIHSS $\%$ changes in relation to developed Asymptomatic ICH, and developed other complication other than ICH post I.V rt-PA injection in our studied group

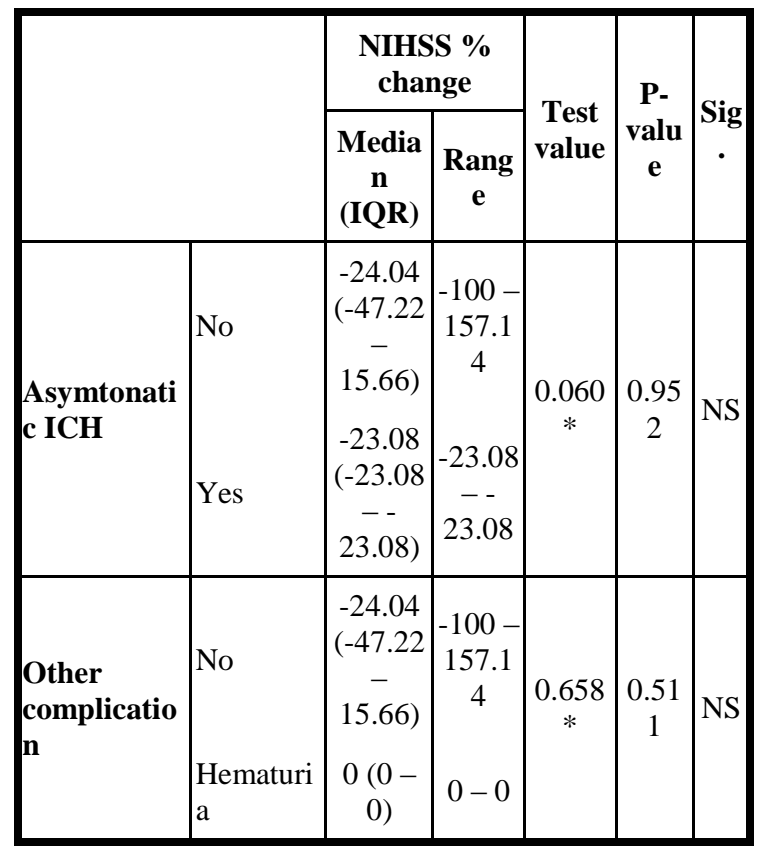

There were significant values between NIHSS \% changes in relation to findings in $\mathbf{C T}$ brain follow up 24 hours post injection as (P-value < 0.05 ) as showed in table (7).

Table (7): The comparison between NIHSS $\%$ changes in relation to findings in CT brain follow up 24 hours post injection in our studied group

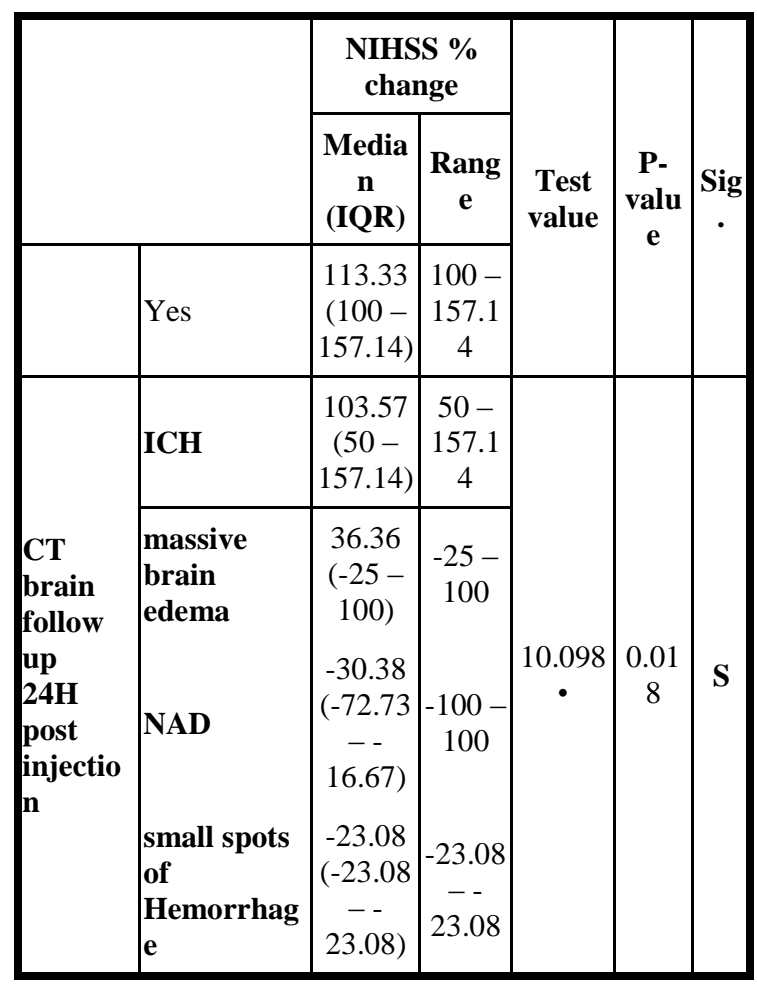




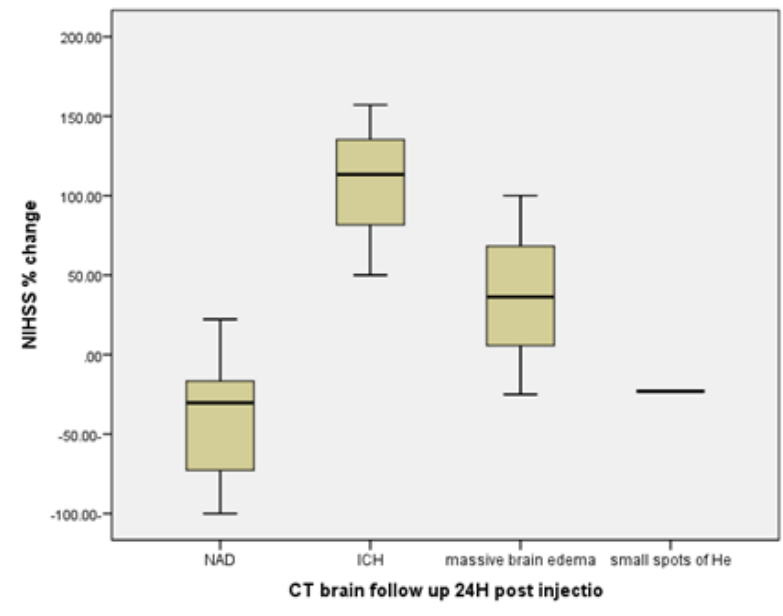

Figure (2): CT brain follow up $24 \mathrm{H}$ post injection

\section{DISCUSSION}

In Egypt difficulties in patient recognition of stroke symptoms, delays in seeking appropriate care, are the most important reasons for low usage rates of I.V rt-PA as in our study ${ }^{(5)}$.

On religious aspect, we could not set a control group not receiving I.V rt-PA to compare the results between the patients who treated with rt-PAby AIS patients presented in time window but not thrombolysed.

The important delay from stroke onset to ER compared with Gurav et al ${ }^{\text {(6) }}$ was explained by the fact that most patients and their relatives had lack of awareness of stroke symptoms, failure of primary care physician to recognize symptoms and signs of stroke.

The important delay to needle time was explained by prehospital delay, lack of infrastructure and short narrow the therapeutic window of the treatment (4.5 hours); and the clinical, imaging, and laboratory evaluation of rt-PA in a patient with AIS is complicated ${ }^{(6)}$.

$19(65.5 \%)$ of 29 patients had significant early improvements within 24 hours post rt-PA infusion, which higher than Chtaou et al. ${ }^{(8)}$ which showed 25 of 52 patients (48\%).Hokmabadi et al ${ }^{(9)}$ who showed lower rate $\mathbf{( 6 . 4 \% )}$

All patients with symptomatic ICH (10.3 \%) were died.Patients with either symptomatic or asymptomatic ICH had less favorable outcomes and higher mortality rates compared to patients without ICH.

The main barriers of thrombolysis in our study included:Lack of public awareness and Inaccessibility to Emergency Medicine Service and good infrastructural system that prevent a delay in time.

Recommendations: A series of teaching courses must be performed, to educate physicians in emergencies on the importance of time window. These will result in acceptable stroke onset to needle time in our hospitals.

More rapid identification and evaluation in the emergency department, also could be responsible for the lower rate of ICH and better outcomes.

\section{References}

1. CADISS Trial Investigators (2015): Antiplatelet treatment compared with anticoagulation treatment for cervical artery dissection (CADISS): a randomised trial. The Lancet Neurology, 14(4): 361367.

2. Muthaian R, Minhas G, Anand A (2012): Pathophysiology of stroke and strokeinduced retinal ischemia: Emerging role of stem cells. Journal of cellular Physiology, 227(3):1269-1279.

3. Barreto A (2011): Intravenous thrombolytics for ischemic stroke. Neurotherapeutics, 8(3): 388-399.

4. Zaidat O, Liebeskind D, Edgell R, AmlieLefond $\mathrm{C}$, Kalia $\mathrm{J}$, Alexandrov A (2012): Clinical trial design for endovascular ischemic stroke intervention. Neurology, 79(13

Supplement 1), S221-S233.

5. Urimubenshi G, Cadilhac D, Kagwiza J, Wu O, Langhorne P (2018): Stroke care in Africa: A systematic review of the literature. International Journal of Stroke, 17(4):749-753.

6. Gurav SK, Zirpe KG, Wadia RS, Pathak MK, Deshmukh AM, Sonawane RV, Goli N (2015): Problems and limitations in thrombolysis of acute stroke patients at a tertiary care center. Indian journal of critical care medicine: peer-reviewed, official publication of Indian Society of Critical Care Medicine, 19(5): 265.

7. Chtaou N, Rachdi L, El Midaoui A, Souirti Z, Wahlgren N, Belahsen MF (2016): Intravenous thrombolysis with rtPA in stroke: experience of the moroccan stroke unit. The Pan African Medical Journal, 24:70-77.

8. Sadeghi-Hokmabadi E, Farhoudi M, Taheraghdam A, Hashemilar M, 
Intravenous Thrombolysis with rt-PA in Patients....

Savadi-Osguei D, Rikhtegar R, Mirnour

R (2016): Intravenous recombinant tissue plasminogen activator for acute ischemic stroke: a feasibility and safety study.

International Journal of General

Medicine,9:361-367. 